\title{
Mudança Tecnológica na Agricultura: uma revisão crítica da literatura e o papel das economias de aprendizado
}

José Eustáquio Ribeiro Vieira Filho' ${ }^{1}$ e José Maria Ferreira Jardim da Silveira²

Resumo: O presente estudo faz uma revisão crítica da literatura sobre a mudança tecnológica na agricultura e uma breve descrição da abordagem alternativa do crescimento agrícola. Na literatura tradicional, apresentam-se a difusão tecnológica, o dualismo produtivo e a inovação induzida. Na visão dinâmica, mostra-se a abordagem alternativa do crescimento agrícola, bem como a importância das inovações e da capacidade de absorção de conhecimentos. A grande limitação dos estudos tradicionais, ao abordarem o crescimento agrícola, é a ausência de explicações da busca tecnológica e do processo de aprendizado. A compreensão do setor agrícola deve identificar que nem todo o desenvolvimento tecnológico e geração de novos conhecimentos estão cristalizados nos insumos produtivos. A agricultura não funciona por meio de agentes receptores passivos de tecnologias. O processo de inovação na agricultura é estruturado dentro de complexos arranjos produtivos e de instituições (públicas e privadas) promotoras do conhecimento. Os investimentos e as atividades de experimentação são exercidos dentro da unidade produtiva, gerando maior estoque de conhecimento e ampla capacidade de absorção, além de estimular a apropriação privada dos ganhos produtivos.

Palavras-chaves: Mudança tecnológica, conhecimento, capacidade de absorção, inovação.

Abstract: This paper presents a critical review on the literature related to technological change in agriculture, and makes a brief description of the alternative approach for agricultural growth. In the traditional literature, technological diffusion, productive dualism and induced innovation are studied. In the dynamic view, the alternative approach of agricultural growth is discussed together with the importance of innovation process and the ability to explore external knowledge. The major limitation of traditional thinking about agricultural growth is the absence of explanations on innovation and learning process. The agricultural sector must recognize that not all technological development and new knowledge come with the acquisition of inputs. Agriculture does not cater to the means of agents who

\footnotetext{
1 Pesquisador do Instituto de Pesquisa Econômica Aplicada (Ipea) e Professor da Universidade de Brasília (UnB). E-mail: jose.vieira@ipea.gov.br

2 Professor da Universidade Estadual de Campinas (Unicamp). E-mail: jmsilv@eco.unicamp.br
} 
will simply be the receptors of technology. The innovation process within agriculture is organized through complex, production systems, as well as institutions, both private and public, which promote knowledge. Investments and experimentation activities occur within the unit of production, thus creating a wider knowledge stock and a larger absorptive capacity, in addition to fostering the private appropriation of productive gains.

Key-words: Technological change, knowledge, absorptive capacity, innovation.

Classificação JEL: B52, O3, O31 e Q16.

\section{Introdução}

Os estudos sobre a inovação tecnológica na agricultura, especialmente os realizados no Brasil desde a década de 1960, vêm refletindo as profundas mudanças ocorridas no setor: da estagnação aos elevados ganhos de produtividade. De acordo com Melo (1983), havia o debate que preconizava a melhoria da infraestrutura de importação de grãos (trigo, principalmente) para fazer frente ao grave problema de abastecimento que se delineava, caso inimaginável com o progresso alcançado pela agricultura brasileira no período mais recente. Este progresso pode ser verificado pelo crescimento da produtividade total dos fatores, notadamente após a década de 1970 e com sua intensificação nos anos 90 em diante (GASQUES et al., 2010; 2012).

Tratando-se especificamente da questão tecnológica, há uma interessante literatura que reflete a realidade da transformação agrícola dos anos 60 e 70 . O modelo proposto por Schultz (1964) apontava para as vantagens da modernização da agricultura, o que Vieira Filho (2009) chamou de tecnologia embarcada guiada pela indústria fornecedora de insumos modernos. Porém, para o caso brasileiro em particular, as pesquisas procuravam explicar as dificuldades de se aplicar e interpretar essa abordagem, já que o crescimento da produção era visto como dependente do conteúdo tecnológico cristalizado nos insumos, que eram em grande parte importados do mercado externo. Com a criação da Empresa Brasileira de Pesquisa Agropecuária (Embrapa), em 1973, o problema se desloca para a adequação da política tecnológica à dotação de fatores do País, assumindo importância o modelo da inovação induzida, o qual foi popularizado por Hayami e Ruttan (1988) e formalizado nos trabalhos de Binswanger (1974a; 1974b).

Em resumo, essa literatura aborda a questão da tecnologia agrícola, discutindo a adoção e a difusão tecnológica, a modernização e a diversidade do setor agrícola, bem como a inovação induzida. Tem-se uma discussão das condicionantes da adoção tecnológica que, com o passar do tempo, intensifica a preocupação em como dirigir o processo de geração de inovações. Acreditava-se que qualquer problema ou distorção no processo de adoção e difusão de tecnologias agrícolas se associava a gargalos no fornecimento de insumos modernos. Para corrigir a deficiência em produtividade, bastaria a realização de investimentos na cadeia fornecedora de tecnologia.

Todavia, em um momento em que o desempenho da agricultura brasileira se apresenta como resultado do processo de inovação, novas abordagens são demandadas, para além do modelo de insumos modernos. Tais abordagens buscam aprofundar estudos anteriores, como o de Possas et al. (1996), que de certa forma deu pouca importância para o vínculo entre a complexidade do processo de adoção e as trajetórias de tecnologias industriais voltadas para a agricultura.

O trabalho está dividido em duas partes: i) uma revisão crítica da literatura tradicional sobre inovações tecnológicas e ii) um tratamento sucinto da abordagem baseada na visão evolucionista de compreensão do crescimento agrícola. $\mathrm{O}$ presente texto procura recuperar alguns dos 
principais trabalhos da literatura para entender a importância da mudança tecnológica. Há a constatação de que a agricultura não é um setor residual da economia e que a mesma incorpora continuamente inovações tecnológicas e, por consequência, progresso técnico.

A primeira parte apresenta o estudo clássico de Griliches (1957), o modelo de desenvolvimento dual de Paiva (1971) e o enfoque da inovação induzida de Hayami e Ruttan (1988). O estudo de Griliches (1957) se refere à introdução do milho híbrido nos Estados Unidos. A seleção deste artigo aponta, a partir de um simples modelo epidemiológico de difusão, para os problemas sistêmicos que afetam a adoção e o uso de um pacote tecnológico nas diferenças entre o que ocorreu na produção agrícola de Iowa, região mais próspera, e do Alabama, mais atrasada.

O dualismo de Paiva (1971) é discutido numa tentativa de explicar a relação entre um segmento tradicional retardatário e uma moderna agricultura em crescimento. O pessimismo de Paiva reflete o pensamento de uma época, já mencionada acima, mas também aponta para a importância de fatores que transcendem o simples processo de adoção. Transformar um conhecimento experimental em uma tecnologia superior exige um processo de interação entre seus distintos participantes que vai além da simples comunicação, como nos enfoques extensionistas. Logo, a superação do mecanismo de autocontrole da inovação não é trivial. Assinalou-se a importância da educação como solução do problema, que se apresentava de difícil solução naquele período.

Por fim, tem-se a exposição do enfoque teórico de Hayami e Ruttan (1988) da inovação tecnológica induzida, sendo os preços relativos dos insumos sinalizadores das direções inovativas. Acredita-se que, de forma um tanto paradoxal, tais estudos procuravam afirmar a hegemonia do mercado no processo de decisão de inovar. Como mostra Silveira (2002), o próprio Ruttan (1992), anos depois, reconhecerá a importância dos arranjos institucionais para captar, antecipadamente, os sinais da escassez que governariam os preços relativos indutores da inovação.
A segunda parte visa identificar caminhos de superação ou mesmo questões relevantes que contribuem para reduzir a limitação microeconômica tratada na primeira seção. A literatura tradicional ignora alguns importantes mecanismos internos, sejam o processo de aprendizado (cumulativo no tempo), a busca de diferenciação e estratégias competitivas e o processo formal de pesquisa e desenvolvimento. Tais mecanismos demandam mais que aceitar a importância - irrefutável - da indústria de insumos e de equipamentos para o processo de modernização. Há inclusive que trabalhar a ideia - bastante polêmica - de que a dinâmica da produção agrícola influencia no rumo das trajetórias tecnológicas (VIEIRA FILHO e SILVEIRA, 2011). Outro ponto interessante é o de pensar em agricultores (ou rede de agentes) schumpeterianos, em que a inovação é estratégica para crescimento do lucro e manutenção das vantagens competitivas por um período mais longo que o preconizado por modelos de competição pura (VIEIRA FILHO, CAMPOS e FERREIRA, 2005).

Portanto, espera-se avançar, considerando-se as características do caso brasileiro, a partir dos trabalhos de Salles Filho (1993); Possas, Salles Filho e Silveira (1996); Vieira Filho, Campos e Ferreira (2005); Vieira Filho (2004; 2009) e Vieira Filho e Silveira (2011), na busca de explicações sobre o caráter dinâmico do crescimento agrícola, baseado nas inovações, nas trajetórias tecnológicas e na ampliação da capacidade de absorção de conhecimento dos agricultores.

\section{Evolução do debate teórico na agricultura: revisão crítica da literatura tradicional}

\subsection{Adoção e difusão tecnológica na agricultura}

Os estudos de Griliches (1957) e de Mansfield (1961) tentaram identificar as regularidades empíricas dos caminhos da difusão tecnológica, tipicamente representadas por curvas 
Figura 1. Percentual médio de milho plantado com semente híbrida nos Estados Unidos, de 1932 a 1956.

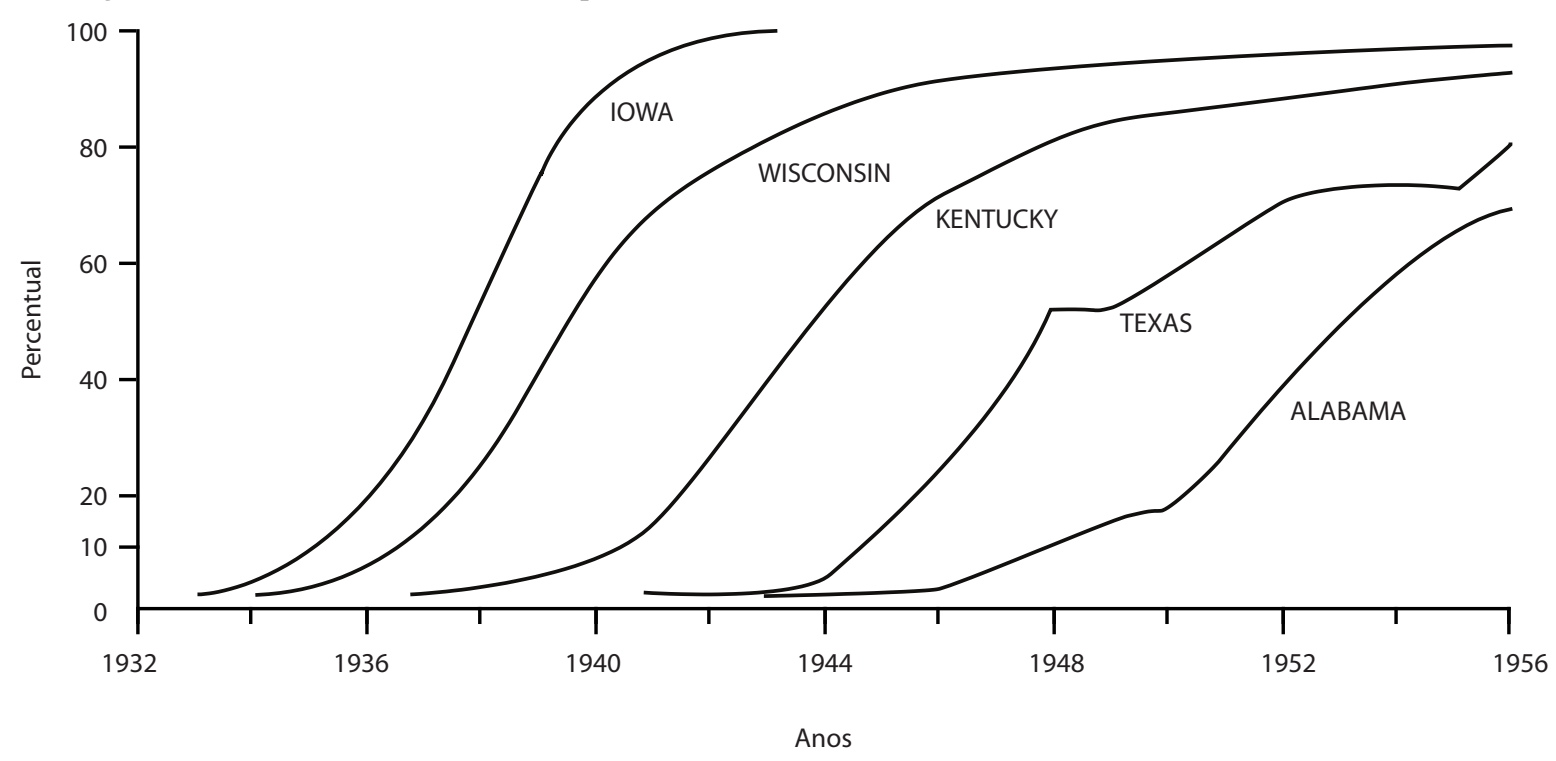

Fonte: Griliches (1957, p. 502).

logísticas $^{3}$. Na abordagem epidemiológica de Mansfield (1961), a difusão é geralmente puxada pelas expectativas de ganhos produtivos de uma inovação e conduzida por uma progressiva disseminação de informações sobre a técnica e as características econômicas. Então, a difusão é interpretada como um processo de ajuste para algum equilíbrio de longo prazo através da capacidade de aprendizado dos potenciais usuários da tecnologia ${ }^{4}$.

Em Griliches (1957), tem-se por objetivo analisar em quais circunstâncias a tecnologia é gerada e propagada na agricultura americana em meados do século passado. As pesquisas agronômicas relativas ao desenvolvimento do milho híbrido nos Estados Unidos foram

3 Para uma boa resenha e explicação dos modelos de difusão tecnológica baseados em curva logística, conferir Geroski (2000).

4 Silverberg, Dosi e Orsenigo (1988) identificam na literatura econômica três abordagens básicas sobre a difusão: i) os modelos epidemiológicos - Griliches (1957) e Mansfield (1981); ii) os modelos de difusão equilibrada - David (1969), Davies (1979) e Stoneman e Ireland (1983) - apenas para algumas citações, apud Silverberg, Dosi e Orsenigo (1988) e iii) os modelos evolucionários - Iwai (1981a, 1981b), Nelson e Winter (1982), Silverberg, Dosi e Orsenigo (1988) e Metcalfe (2002). iniciadas no começo do século XX; porém, a primeira aplicação em escala comercial data dos anos 30. Desde então, a semente híbrida se difundiu rapidamente pelo território americano, especificamente nos Estados de Iowa, Wisconsin, Kentucky, Texas e Alabama (região chamada por "Cinturão do Milho", devido à posição de destaque na produção agrícola de milho).

A adoção da semente híbrida não deve ser analisada apenas como uma introdução simples de um insumo produtivo imediatamente adaptável às condições de cada região. Além das diferentes taxas de adoção da semente híbrida pelos agricultores, é válido explicar as diferenças de desenvolvimento regional em termos de aceitação e viabilidade produtiva. Pela Figura 1, tem-se o percentual médio de milho plantado com semente híbrida por região ao longo do tempo.

Conclui-se que a adoção tecnológica, neste caso, segue a uma taxa de crescimento exponencial num primeiro momento e, subsequentemente, o crescimento se dá por meio de taxas marginais decrescentes. Cabe observar que este movimento não é delineado ao longo de pontos de equilíbrio, os quais podem ou não se alterar ao longo do tempo. Entretanto, o caminho de ajuste se move, 
consistentemente, de um ponto inicial para uma nova posição de equilíbrio. As novas variedades são adaptadas a alguns nichos regionais.

Embora a produção da semente híbrida tenha sido desenvolvida a partir de estudos da genética e da estatística experimental [cuja contrapartida moderna é a biotecnologia que utiliza tanto os conhecimentos passados, do melhoramento genético, quanto da biologia molecular, como mostra Salles Filho (1993)], existem várias especificidades e restrições geográficas, as quais são menores no estado de Iwoa e mais intensas no Alabama ${ }^{5}$. Portanto, as sementes são mais adaptadas ao primeiro do que ao segundo estado, tendo este último uma introdução tecnológica mais atrasada e uma taxa de adoção menos acelerada. Para exemplificar, os produtores de Iwoa que adotaram a nova tecnologia, ao longo de quatro anos, passaram de 10 a $90 \%$ do total. Em outras regiões de menor produtividade, este ajuste se processa de forma mais lenta ao longo do tempo.

A literatura de difusão tecnológica, conforme Davies (1988) e Geroski (2000), apresenta dois modelos básicos para explicar o processo de difusão: o modelo que parte de uma fonte central e outro baseado no contágio, na comunicação "boca-a-boca", também chamado de modelo epidemiológico. Este último, adotado pelo trabalho de Griliches (1957), parte de uma equação diferencial simples, em que $p$ é o número (ou a proporção de adotantes) a cada momento $t$, cuja evolução no tempo é ponderada pelo reverso da distância em que o processo se encontra de atingir o seu potencial máximo $\left(\mathrm{k}-\mathrm{p}_{\mathrm{t}}\right.$; sendo $\mathrm{k} \mathrm{o}$ potencial de agentes inovadores). No lado direito da equação, o parâmetro $\beta$ dá a força do processo de adoção. A equação (1) abaixo representa o processo.

5 Conforme relatório da FAO (2000, p. 254), "[...] cet « effet Alabama » s'est fait sentir dans tous les pays en développement. Les pays dépourvus de capacité de recherche d'adaptation n'ont pas tiré grand bénéfice des technologies créées à l'étranger". Em outros termos, através do enfoque de Coehn e Levinthal (1989 e 1990), este efeito Alabama se faz presente nas regiões em que os agricultores são desprovidos de adequada capacidade de absorção.

$$
\frac{d p_{t}}{d t} \cdot \frac{1}{\left(k-p_{t}\right)}=\beta \frac{p_{t}}{k}
$$

A agregação desse processo resulta em uma função logística de crescimento que, segundo o autor, é a que melhor se ajustou aos dados por estado e produção com o uso de sementes híbridas, reduzindo-se as diferenças regionais em três parâmetros estimados (data da primeira disponibilidade comercial - origins, taxa de adoção tecnológica - slopes e teto potencial de agentes inovadores - ceilings). A curva logística ${ }^{6}$ é definida pela equação (2).

$$
P=\frac{K}{1+e^{-(\alpha+\beta . t)}}
$$

Ao manter a correspondência com a equação (1), tem-se que $P$ é o percentual plantado com semente híbrida, $K$, o teto potencial de agentes inovadores (um valor de equilíbrio), $t$, a variável tempo, $\beta$, o parâmetro relacionado à taxa de adoção ou coeficiente de crescimento, e $\alpha$ é uma constante de integração, que posiciona a curva numa escala do tempo. O modelo é, portanto, não linear, refletindo o fato de que a curva é assintótica em 0 e em K. Tal função tem uma propriedade interessante: a curva apresenta um ponto de inflexão que tem sentido econômico, uma vez que a partir desse ponto as taxas de adoção são positivas, mas decrescentes, até desaparecerem quanto mais próximas ficam do valor máximo.

Todavia, a linearização do modelo é simples e também permite uma interpretação econômica ao resultado. Basta dividir os dois lados da equação (2) por $\left(K-P_{t}\right)$, a distância a cada instante de tempo do ponto de saturação da difusão, que dá o potencial de adoção. Isto feito, cria-se uma nova variável, a relação entre o nível da adoção

\footnotetext{
6 Como crítica à curva logística aqui apresentada, pode-se notar que o caráter estático dos parâmetros se torna dinâmico ao incluir a diferenciação dos agentes (inovadores e imitadores), bem como ao incorporar a capacidade de absorção de conhecimentos externos. Em Trigo et al. (2002), tem-se simulações para diferentes taxas de adoção e para distintos tetos potenciais, em diagnósticos e prognósticos da transferência de tecnologia agrícola.
} 
$P_{t}$ e o potencial da adoção $\left(K-P_{t}\right)$, que é explicada por $(\alpha+\beta \mathrm{t})^{7}$.

Os resultados mostraram que o uso de milho híbrido é largamente guiado pela expectativa dos ganhos de produtividade e que as regiões pioneiras no uso da semente foram as mais beneficiadas, o que indica uma vantagem dos agentes que saem na frente na corrida tecnológica. Quanto maior a eficiência da tecnologia em produzir retornos, maior será a taxa de adoção. Diferenças nas taxas de adoção são relacionadas à produtividade da semente híbrida, bem como à imperfeição do conhecimento. Quanto maior a transformação produtiva da tecnologia, maior será a preocupação do gerente agrícola em buscar o novo conhecimento e informação. A data da primeira disponibilidade comercial é determinada pelo lado da oferta, enquanto que a taxa de adoção é relativa às condições de demanda e explicada por diferentes produtividades em distintas regiões.

O teto potencial de usuários é interpretado como o percentual de plantações híbridas num equilíbrio de longo prazo. As diferenças no percentual em que o uso de sementes híbridas se estabilizará são o resultado de longo prazo da procura de fatores. É assumido, então, que as condições de oferta de sementes, no longo prazo, são as mesmas em todas as regiões, o mesmo percentual aumenta a produtividade entre as variedades convencionais (ou de polinização aberta) ao mesmo preço relativo. Entretanto, a mesma superioridade técnica deve significar diferenças múltiplas em várias regiões. Embora Griliches (1957) reconheça que o potencial de usuários mude ao longo do tempo em certas regiões, numa primeira aproximação tal autor ignorou o problema, já que estudou a adoção do milho híbrido nas áreas mais produtivas dos Estados Unidos.

7 Griliches (1957) baseou-se no trabalho de J. Berkson, publicado no Journal of American Statistical Association, em 1953, para justificar a existência de uma aproximação linear entre o logaritmo natural desta "nova variável" e $(\alpha+\beta \mathrm{t})$, utilizando o método de máxima verossimilhança para estimar os parâmetros.
Não há dúvida da relevância do trabalho de Griliches (1957); porém, podem-se fazer algumas críticas quanto à relativa estabilidade dos parâmetros do processo de difusão tecnológica. Algumas dessas críticas já foram apontadas na última nota de rodapé do estudo deste autor, em que uma das explicações da baixa taxa de adoção tecnológica estaria ligada ao resultado de alguns fatores econômicos, variáveis de impacto sociológico. No que concerne à referida nota,

In this context one may say a few words about the impact of sociological variables. It is my belief that in the long run, and cross-sectionally, these variables tend to cancel themselves out, leaving the economic variables as the major determinants of the pattern of technological change. This does not imply that the sociological variables are not important if one wants to know which individual will be first or last to adopt a particular technique, only that these factors do not vary widely cross-sectionally. Partly this is a question of semantics. With a little ingenuity, I am sure that I can redefine 90 percent of the sociological variables as economic variables. Also, some of the variables I used, e.g., yield of corn and corn acres per farm, will be very highly related cross-sectionally to education, socio-economic status, level-of-living, income, and other sociological variables. That is, it is very difficult to discriminate between the assertation that hybrids were accepted slowly because it was a poor corn area and the assertation that the slow acceptance was due to poor people. Poor people and poor corn are very closely correlated in the U.S. Nevertheless, one way find a few areas where this is not so. Obviously, the slow acceptance of hybrids on the western fringes of the Corn Belt, in western Kansas, Nebraska, South Dakota, and North Dakota was not due to poor people, but the result of economic factors, poor corn area and vice versa $^{8}$ (GRILICHES, 1957, p. 522).

O debate em torno do trabalho de Griliches (1957) perdurou por bastante tempo. Uma resposta às críticas apresentadas ao longo

\footnotetext{
8 Apenas para o grifo desta citação, cf. Griliches (1980, p. 1464). Veja que o autor se sente na obrigação de escrever uma nota técnica, passados 24 anos da publicação de seu estudo, o que não é usual na academia. Porém, dada a repercussão dos seus resultados, esta resposta foi permitida.
} 
deste período em relação ao método de análise da difusão do milho híbrido foi publicada em Griliches (1980). Ao fazer uma reavaliação do seu estudo, o autor reespecificaria em seu modelo original as transformações do teto potencial de usuários ao longo do tempo (já que tal parâmetro não é constante e pode, perfeitamente, ser endógeno na função logística), algo que, em certa medida, é objeto de crítica deste trabalho.

O processo de difusão enfatiza o papel do tempo e das informações numa transição de uma tecnologia para o consumo e produção de outra. Uma vez que grande parte dos dados interessantes é não observável, o tempo é visto como uma proxy em pelo menos três conjuntos distintos de força: i) na redução do custo no tempo, como resultado do processo de aprendizado e dos avanços cumulativos do conhecimento tecnológico; ii) no montante depreciado de capital e iii) na difusão das informações ou conhecimento, evidenciando a capacidade e a produtividade de cada indivíduo (GRILICHES, 1980).

Como pode ser entendido, apenas o terceiro conjunto foi objeto de análise do que se convencionou chamar de variáveis sociológicas ou econômicas. Quanto aos outros dois conjuntos de forças, trabalhos mais recentes e que seguem a abordagem evolucionária podem trazer explicações de como o teto muda ao longo do tempo. A difusão de novas técnicas ou novos produtos pode ser vista em condições de incerteza, racionalidade limitada e endogeneidade das estruturas de mercado num processo desequilibrado, como amplamente estudado por Iwai (1981a, 1981b), Nelson e Winter (1982), Silverberg, Dosi e Orsenigo (1988) e Metcalfe (2002).

\subsection{Modernização e dualismo tecnológico}

As aglomerações econômicas propiciam vantagens locacionais e ganhos advindos da proximidade de um centro de crescimento, no qual a atmosfera industrial cria um ambiente receptivo às inovações e aos empreendimentos (em outros termos, economias externas marshallianas).
No sentido geográfico, o crescimento é apresentado de forma desequilibrada. Há, portanto, um desenvolvimento dual entre regiões progressivas e atrasadas, sendo o progresso explicado pelo crescimento industrial ${ }^{9}$.

É com base no argumento de polos de crescimento que a análise sobre o setor agrícola em Paiva (1971) se fundamenta. Contudo, embora haja a ideia clara de diversidade entre os agentes, a visão da agricultura como um setor retardatário em relação à indústria é ponto fundamental para explicar o autoajuste setorial, constatação que será percebida com a apresentação do modelo. Além disso, o progresso técnico agrícola é visto de forma exógena ao crescimento e desenvolvimento econômico.

Em Paiva (1971), tem-se um debate da questão tecnológica, especificamente na convivência de dois tipos de agricultura - uma tradicional e outra moderna ${ }^{10}$. Nos países em desenvolvimento, existem agricultores com alto desenvolvimento tecnológico, que empregam modernas técnicas recomendadas pelos centros de experimentação e pesquisa, bem como agricultores em estágio de desenvolvimento atrasado, que mantêm baixos níveis de adoção e conhecimento tecnológico.

A diversidade se dá no nível tecnológico entre os agricultores, as regiões e os produtos. Neste último, podem-se encontrar três classes de produtos numa mesma região. A primeira representaria produtos em que a grande parte dos agricultores utiliza técnicas modernas, não havendo espaço aos agricultores com técnicas tradicionais. A segunda, inversamente à primeira, seria de produtos em que a maior parcela dos produtores emprega técnicas tradicionais sem o interesse da entrada de agricultores modernos

9 Cf. Perroux (1977) e Hirschman (1977) para uma discussão clássica do conceito de pôle de croissance (polos de crescimento).

10 O modelo sobre dualismo tecnológico apresentado por Paiva (1971) foi objeto de diversos comentários, sendo dois destes de relativa importância - Nicholls (1973) e Schuh (1973), que foram posteriormente avaliados por Paiva (1973). Após amplo debate acerca de seu estudo, Paiva (1975) faz uma síntese das principais ideias criadas em torno das questões tecnológicas na agricultura e de seu próprio modelo. 
nesse segmento. Por fim, na classe onde se encontra o maior número de produtos, tem-se a coexistência de agricultores modernos e tradicionais.

No modelo de dualismo tecnológico, existem dois grupos de variáveis. O primeiro que diz respeito à qualificação dos produtores (conhecimentos técnicos, disponibilidade de recursos, capacidade gerencial, acesso ao financiamento etc.) e o segundo referente aos preços dos fatores (ou insumos produtivos) e dos produtos, além de considerar as distâncias dos mercados, o custo do transporte, a facilidade de armazenamento e a eficiência da comercialização. Tanto a qualificação quanto o preço dos insumos e produtos explicam, embora não completamente, grande parte das distorções entre os agricultores e as regiões. Quanto às diferenças entre produtos, nada se infere a partir destes dois grupos de variáveis.

O processo de modernização da agricultura é analisado tanto na fase de adoção quanto na de difusão tecnológica. A adoção se caracteriza pela escolha do agricultor em usar ou não técnicas modernas, sendo a tomada de decisão uma análise microeconômica. A difusão, ao contrário, caracteriza-se por um processo mais amplo que leva em consideração os resultados agregados da adoção, sendo, portanto, um estudo do ponto de vista macroeconômico.

Quanto ao processo de adoção, a técnica moderna se mostra mais rentável do que a tradicional, no momento em que a diferença entre a receita total e os custos produtivos ${ }^{11}$ for mais elevada do que a técnica tradicional. Em termos algébricos, a substituição de uma técnica moderna por uma tradicional se daria quando atendida a seguinte condição:

\footnotetext{
11 Nesta observação, vale lembrar que os custos fixos são iguais a zero, ou idênticos entre as duas técnicas. A ótica do rendimento líquido foi incluída por Paiva (1975), após tomar nota do modelo de inovação induzida do início da década de 1970, reproduzido em Hayami e Ruttan (1988). De qualquer maneira, Griliches (1957) já havia colocado ênfase na lucratividade da mudança do milho de polinização aberta para o milho híbrido, de forma a explicar o crescimento diferenciado da taxa de adoção e da disponibilidade produtiva de variedades localmente adaptadas pelas firmas fornecedoras.
}

$$
\left(P_{q} \cdot Q^{m}\right)-\left(P_{x}^{m} \cdot X^{m}\right)>\left(P_{q} \cdot Q^{t}\right)-\left(P_{x}^{t} \cdot X^{t}\right)
$$

sendo $Q^{m}$ a quantidade produzida com a técnica moderna, $Q^{t}$ a quantidade obtida com técnica tradicional, $X^{m}$ a quantidade de insumos modernos, $X^{t}$ a quantidade de insumos tradicionais, $P_{q}$ o preço do produto, $P_{x}^{m}$ o preço dos insumos modernos e $P_{x}^{t}$ o preço dos insumos tradicionais.

Para uma simplificação, agregam-se insumos modernos (máquinas, fertilizantes, defensivos, benfeitorias etc.) em uma única variável $\left(X^{m}\right)$, assim como insumos tradicionais (terra e trabalho) em outra $\left(X^{t}\right)$. Ocorre que um agricultor utiliza uma combinação mínima de técnicas modernas e tradicionais. Quando o agricultor for considerado moderno, o mesmo utiliza relativamente mais técnicas modernas do que tradicionais. Se o contrário acontecer, as técnicas modernas serão preteridas às tradicionais; então, o agricultor será considerado como tradicional. Neste sentido, a relação renda líquida é dada por:

$$
\begin{aligned}
& \left(P_{q} \cdot Q^{m}\right)-\left(\sum_{i=1}^{n} P_{x i}^{m} \cdot X_{i}^{m}+\sum_{j=1}^{l} P_{x j}^{t} \cdot X_{j}^{t}\right)> \\
& \left(P_{q} \cdot Q^{t}\right)-\left(\sum_{i=1}^{n^{\prime}} P_{x i}^{m} \cdot X_{i}^{m}+\sum_{j=1}^{l} P_{x j}^{t} \cdot X_{j}^{t}\right)
\end{aligned}
$$

sendo $n>n^{\prime}$ e $l>l^{\prime}$, em proporção a ser definida.

Diante do que foi apresentado, a vantagem econômica da técnica moderna em relação à tradicional depende de três relações: i) a comparação entre as produtividades por insumos $\left(Q^{m} / X^{m}\right) /\left(Q^{t} / X^{t}\right)$, sendo o aumento (ou a redução) da produtividade da técnica moderna favorável (desfavorável) às suas vantagens econômicas; ii) a observação entre os preços relativos dos insumos modernos e tradicionais $\left(P_{x}^{m} / P_{x}^{t}\right)$, significando que um aumento dos preços da terra e do trabalho em relação aos insumos modernos favorece o emprego de uma tecnologia moderna e iii) a análise do preço do produto frente ao seu respectivo preço do insumo tanto na agricultura moderna quanto na tradicional $\left(P_{q} / P_{x}^{m}\right.$ e $\left.P_{q} / P_{x}^{t}\right)$, identificando que um crescimento do preço do produto frente ao preço de seu insumo favorece a intensificação do uso do insumo em questão. 
Figura 2. O custo subjetivo de transferência dos produtores.

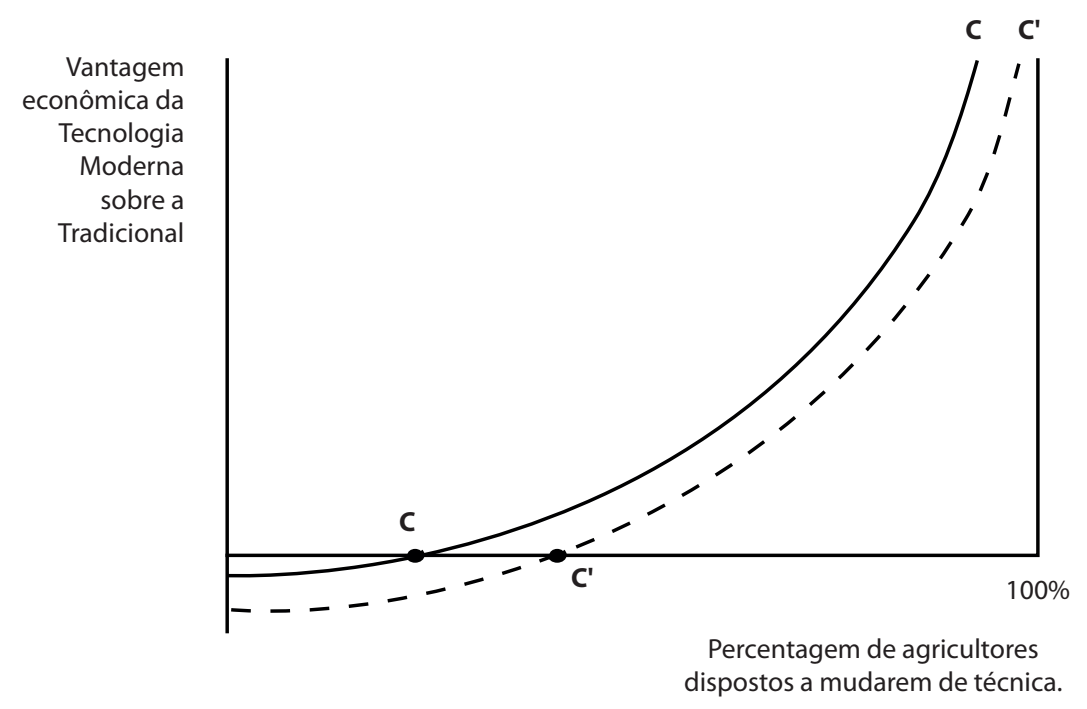

Fonte: Paiva (1971, p. 190).

Em síntese, a vantagem da técnica moderna em relação à tradicional dependerá da produtividade por insumo, dos preços relativos dos insumos modernos e tradicionais e, por fim, da relação de preço do produto com os seus respectivos preços dos insumos. Mudanças em qualquer uma dessas relações podem criar ou não um ambiente favorável ao uso tecnológico e modernização da agricultura. Todavia, deve-se ressaltar que existe um custo subjetivo (ou transacional) em adotar uma nova tecnologia. A adoção tecnológica pode ser confundida com o problema da transferência de um sistema tradicional para o moderno. A vantagem da técnica moderna deve ser elevada o suficiente para cobrir estes custos transacionais, o que estimularia a substituição de um sistema pelo outro. Levando-se em consideração a análise dos custos transacionais, a relação de transferência em favor da técnica moderna é dada por:

$$
R T^{n}-C V^{m}>R T-C V^{t}+C T
$$

sendo $R T$ a receita total, $C V$, o custo variável e $C T$, o custo de transação (ou custo de oportunidade de transferência).

O custo de transação varia de um agricultor para o outro, dependendo da qualificação, das características locais e da cultura inovativa.
A Figura 2 apresenta o custo subjetivo de transferência para uma população de agricultores. A inclinação da curva é função do grau de acesso ao financiamento, do nível de instrução, do empreendedorismo, dentre outras variáveis. Nota-se que, quanto maior for a vantagem econômica da técnica moderna em relação à tradicional, mais elevado será o percentual de agricultores dispostos a se modernizarem, o que favorecerá a transferência. Além disso, se houver uma melhora da cultura inovativa, a curva se deslocará para a direita.

No que tange ao processo de difusão tecnológica, a expansão da técnica moderna depende, por um lado, da vantagem econômica do uso tecnológico e, por outro, de alguns fatores reguladores do crescimento, bem como do desenvolvimento de um setor não agrícola. A difusão das técnicas modernas provoca alterações nos preços do produto e dos insumos tradicionais, mudanças que impedem a modernização mais acentuada. Esse fenômeno pode ser sintetizado da seguinte forma:

i) com a difusão tecnológica de insumos modernos, tem-se um aumento da produtividade, ceteris paribus, uma queda do preço do produto e, posteriormente, 
com uma intensificação do uso tecnológico, vê-se uma redução dos preços dos insumos tradicionais (terra e trabalho) $)^{12}$

ii) por meio da redução do preço do produto, a relação com o preço do insumo se altera $\left(P_{q} / P_{x}^{m}\right)$ e reduz, então, a vantagem da tecnologia moderna; e

iii) em consequência, após a queda dos preços dos insumos tradicionais, tem-se um aumento do preço relativo dos insumos modernos e tradicionais $\left(P_{x}^{m} / P_{x}^{t}\right)$, o que torna a técnica moderna menos vantajosa, ou mesmo desvantajosa ${ }^{13}$.

O fenômeno descrito acima desestimula o processo de modernização agrícola. Com o uso de uma técnica mais moderna, a redução do custo por unidade de insumo deve compensar a redução do preço do produto. Se isso ocorrer, o uso de mais tecnologia continua. O processo de modernização está associado a um mecanismo de autocontrole, já que existem elementos de

12 Em Veiga (1992), no que diz respeito ao efeito treadmill, a difusão tecnológica tem a capacidade de excluir os agricultores atrasados (ou marginalizados do progresso técnico), aumentando, assim, a concentração produtiva. Não obstante, tem-se, de um lado, uma queda no preço do produto e, de outro, uma elevação no preço da terra, o que conduziria a um mecanismo de autocontrole do processo de modernização agrícola. Embora o raciocínio de Veiga (1992) tenha um enfoque da contenção do uso tecnológico distinto do modelo de Paiva (1971), já que o mesmo deteriora a renda do agricultor, os dois autores falham em suas análises por considerar a tecnologia exógena e por não incluir a constante busca por estratégias diferenciadas numa competição entre os agricultores, que acumulam conhecimento por um processo interno de aprendizado.

13 De fato, Paiva (1971) não percebeu que, com a intensificação do processo de difusão tecnológica, tem-se uma redução no preço do insumo moderno, posto os ganhos de escala da indústria fornecedora (que repassa, em parte, menores preços aos consumidores), bem como o aprendizado e a utilização mais eficiente da tecnologia pelos produtores. Se de fato houver uma redução no preço do insumo moderno, conjuntamente com a redução no preço dos insumos tradicionais, os resultados do modelo seriam imprevisíveis, dependendo da magnitude de redução dos preços em geral. Para uma busca na literatura acerca da difusão tecnológica que apresente este tipo de efeito, ver Nelson e Winter (1982), Silverberg, Dosi e Orsenigo (1988) e Metcalfe (2002). desestímulo (redução do preço do produto com queda no preço dos insumos tradicionais), os quais surgem por um processo endógeno do próprio crescimento da modernização. Este mecanismo limita o potencial de difusão tecnológica. Por fim, ao atingir tal limite, o crescimento da modernização fica dependente do crescimento do setor não agrícola ${ }^{14}$.

A introdução tecnológica visa o aumento da produtividade e uma redução do custo de produção. De qualquer forma, nem toda inovação é bem-sucedida e, assim, podem-se distinguir três tipos de técnicas modernas: i) uma em que se tem crescimento do rendimento líquido, através do aumento de produtividade sem reduções de custos marginais - é o exemplo de insumos que necessitam de grande dispêndio de capital fixo, tratores, colheitadeiras, máquinas e equipamentos; ii) outra na qual a produtividade cresce e o custo marginal decresce, referente às técnicas com baixo dispêndio de capital fixo e elevado de custeio - como, por exemplo, fertilizantes, defensivos, rações concentradas, entre outras; e iii) aquelas que proporcionam maior retorno, seja pelo aumento da produtividade com a redução do custo marginal, já que não exigem maiores custos adicionais - são exemplos as técnicas de plantio, do espaçamento adequado das plantas, do manuseio do pasto e do uso de sementes melhoradas ${ }^{15}$. A diferença do terceiro para o segundo tipo é que a renda líquida sempre se manterá superior em comparação ao uso da técnica tradicional, já que não há aumento de despesas, enquanto que no segundo tipo existe.

\footnotetext{
14 Como observado por Schuh (1973), Griliches (1957) reconhece que a relação de preço do produto e do insumo influenciava a taxa de crescimento tecnológico; porém, não percebeu que a própria adoção tecnológica poderia, em alguma medida, deprimir o preço do produto e o preço dos insumos tradicionais, impondo ao processo de modernização o autoajuste. Talvez seja neste ponto a principal contribuição de Paiva (1971) em relação à Griliches (1957), além de uma abordagem do dualismo na agricultura. Entretanto, Paiva (1971) falha ao não abordar a redução de custo com os ganhos de aprendizado, como já especificado na nota anterior.

$15 \mathrm{O}$ uso de sementes de alto rendimento, todavia, incorre frequentemente em elevados custos adicionais.
} 
Portanto, apenas as últimas técnicas mencionadas não sofrem pressão do mecanismo de autocontrole.

Ainda em relação ao mecanismo de autocontrole, pode-se especificar que a queda no preço do produto e no dos insumos tradicionais não estimula a substituição da técnica moderna pela tradicional. Uma vez adotada a nova tecnologia, um retrocesso tecnológico dado por uma mudança conjuntural não acontece, já que os investimentos tecnológicos realizados se apresentam como um custo de saída (sunk costs) ou custos de transferências. Uma das implicações do mecanismo de autocontrole, segundo Paiva (1971, p. 203), é que;

Após atingir o que foi denominado de grau adequado de modernização, a agricultura não pode mais forçar o desenvolvimento pela adoção de técnicas modernas (a não ser no caso de produtos exportáveis), pois mesmo que seja levado a isso, com políticas especiais de incentivo, o mecanismo de autocontrole não permite que sua expansão se processe em escala superior à do desenvolvimento do setor não agrícola ${ }^{16}$.

O mercado externo pode constituir um fator importante num processo de modernização agrícola. Ao absorver a produção de uns poucos países, o mecanismo de autocontrole perderia sua função, posto que a queda de preço do produto no mercado interno não ocorreria. Porém, num segundo momento, com a entrada de mais produtores no mercado internacional, haveria uma queda de preço internacional, o que desestimularia a adoção de mudanças tecnológicas.

16 Uma crítica que se deve fazer é o argumento pessimista quanto ao processo de desenvolvimento agrícola após atingir o grau adequado de modernização. Este raciocínio deixa uma impressão de que a tecnologia não é fonte geradora de renda nos países em desenvolvimento, sendo que, na verdade, o uso de insumos modernos é uma fonte de baixo custo para países em vias de modernização agrícola (mesmo sabendo que os ganhos produtivos da tecnologia podem ser maximizados pelo investimento em capacidade de absorção e em pesquisas experimentais relativas ao caráter regional). Para um comentário análogo e que associa ideias ao trabalho de Hayami e Ruttan (1988), ver Schuh (1973).
Mediante o exposto, as variáveis responsáveis pelo processo de modernização são a produtividade, o preço relativo dos insumos modernos e tradicionais, a qualificação dos agricultores, o custo de transferência tecnológica, o mecanismo de autocontrole, o desenvolvimento do setor não agrícola (sendo este capaz de consumir a produção da agricultura e absorver mão de obra excedente, que viria do processo de mecanização do campo) e as exportações para o mercado internacional.

Acontece que estas variáveis se diferenciam entre agricultores e regiões (ou mesmo países). A desigualdade entre os agricultores varia segundo a qualificação, a manifestação do autoajuste e o custo de transferência tecnológica. Entre regiões, a diversidade se mostra pelo nível alcançado de produtividade, nas relações de preço, no setor não agrícola e no externo. Deve-se ressaltar que os custos de transporte e logística influenciam nos preços do produto e dos insumos, e que, portanto, criam desigualdades no processo de modernização.

Conforme a Figura 3, tem-se uma análise do comportamento agrícola moderno e tradicional, bem como do grau de modernização agrícola em condições de dualidade. O referencial de estudo se baseia nas curvas de oferta e nas condições de demanda. Serão verificadas três situações: uma em que a técnica produtiva prevalecente seja a moderna; outra intensiva em técnicas tradicionais; e, por fim, uma interpretação da dualidade, ou seja, a coexistência das técnicas modernas e tradicionais. $\mathrm{Na}$ parte de cima (letras a e b), serão estudadas situações extremas, havendo especialização em termos de técnicas produtivas. Na parte de baixo (letras c e d), examina-se o caso da dualidade.

O Gráfico a apresenta o caso de uma especialização das técnicas modernas, sendo exemplificadas pela produção de frutas (como figo, uva e pêssego). O uso deinsumos modernos de produção (como variedades de sementes melhoradas, adubação e defensivos) na produção de frutas tem por objetivo aumentar a produtividade agrícola. Com a tecnologia tradicional, baixos índices de produtividade seriam alcançados, já que essa cultura é altamente sensível às doenças e pragas 
Figura 3. Grau de modernização e curvas de oferta em condições de dualidade tecnológica.

(a)

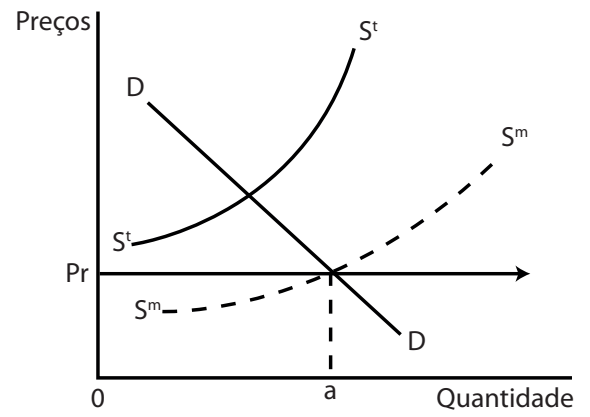

(c)

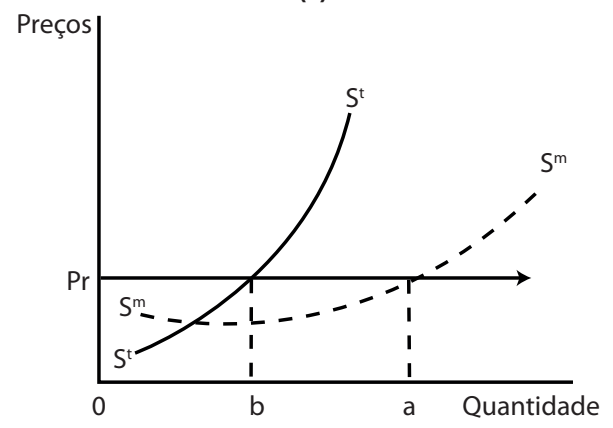

Fonte: Paiva (1971, p. 214-217).

e ao inadequado gerenciamento do solo. Nesse sentido, a curva de oferta com o uso de tecnologia tradicional $\left(S^{t}\right)$ se situaria acima da linha de preço, não permitindo a entrada de produtores com técnicas atrasadas no mercado.

O Gráfico b mostra uma situação inversa, que pode ser o típico exemplo da produção da mandioca. $\mathrm{O}$ custo marginal da produção com a técnica tradicional $\left(S^{t}\right)$ é bastante elástica no seu início (devido às condições favoráveis de clima e abundância de terras), ficando abaixo da curva de oferta da técnica moderna $\left(\mathrm{S}^{\mathrm{m}}\right)$ em sua maior parte. Como este tipo de cultura é resistente às variações climáticas, pragas e doenças, a produção é relativamente satisfatória, sendo o preço definido pelas condições da técnica tradicional. A curva de oferta com a técnica tradicional se torna inelástica apenas para volumes elevados de produção, em que a técnica moderna é preferível. Entretanto, como há baixo consumo do produto, tem-se uma especialização da técnica tradicional na economia. (b)

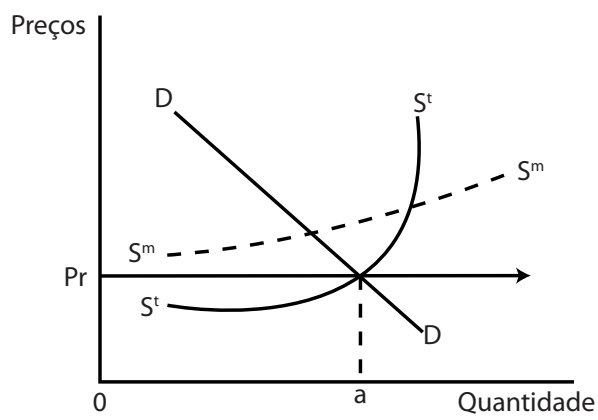

(d)

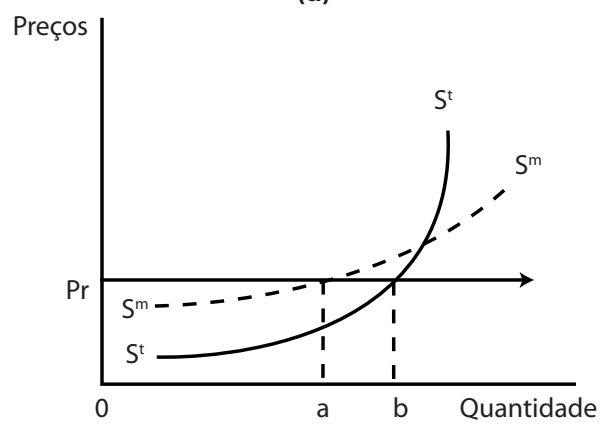

De acordo com o Gráfico c, é possível verificar uma situação de dualidade tecnológica, representada, por exemplo, pelas produções de aves e de ovos. As diferenças de custos não se mostram tão discrepantes, o que favorece o abastecimento do mercado por produtores modernos e tradicionais. No que se refere à técnica tradicional, os custos produtivos se iniciam num patamar baixo, mas com uma forte mudança de sua elasticidade. Esta situação é explicada, em certa medida, pela produção caseira, que apresenta baixo custo e de fácil manutenção pelo pequeno produtor. Quando a produção aumenta, o risco a doenças e pragas se eleva muito, o que favorece o uso de tecnologias (seleção de reprodutores, rações, medicamentos veterinários etc.). Nesse sentido, mesmo com a oferta dos grandes produtores, com o uso de técnicas modernas, há espaço para a produção caseira, que atende porções pontuais do mercado.

Por fim, pelo Gráfico $\mathrm{d}$, há um caso de dualidade, mas inverso ao exemplo anterior. 
Esta situação é representativa, por exemplo, da produção de milho, que é dominada pela técnica tradicional, já que as variedades tradicionais se encontram adaptadas às diversas condições regionais. A produção da agricultura tradicional (b) é maior do que a da moderna adaptada (a). As sementes híbridas, fertilizantes, máquinas, tratores e colheitadeiras aumentam a produtividade do milho, mas o consequente crescimento dos custos não favorece uma transferência para as técnicas mais modernas.

\subsection{Inovação induzida}

O modelo de inovação induzida discutido por Hayami e Ruttan (1988) é uma tentativa de desenvolver uma teoria integrada ao desenvolvimento agrícola e de incorporar mudanças tecnológicas e institucionais. Todavia, a incorporação não é realizada por completo, já que, no fundo, a interpretação, como será apresentada, não passa de uma análise neoclássica ${ }^{17}$ de deslocamento da fronteira de produção com pontos de equilíbrio determinados pelas mudanças dos preços relativos dos insumos, normalmente uma combinação que economiza trabalho ou capital. É como se trabalhar nos pontos de tangência das curvas isoquantas e isocustos, sendo estas últimas não lineares. Portanto, o deslocamento da curva de produção, mesmo que haja mudanças nos preços relativos ao longo do tempo, promove a mudança técnica ${ }^{18}$, a qual continua como um fator residual ${ }^{19}$.

De acordo com o estudo teórico de Hayami e Ruttan (1988), a inovação técnica visa economizar

17 Para uma resenha da tecnologia na agricultura sob o enfoque neoclássico, leia Silva (1995).

18 Seguindo a explicação dada por Sadoulet e De Janvry (1995), mudança tecnológica está associada às mudanças nos parâmetros da função de produção, enquanto que mudança técnica se deve à busca de eficiência alocativa dos agentes face às mudanças nos preços relativos dos fatores.

19 Para uma abordagem alternativa, que trabalha com a mesma ideia de alterações dos preços relativos dos insumos, mas que de fato incorpora de forma endógena a tecnologia agrícola e o comportamento schumpeteriano, ver a discussão da curva de produção com proporções fixas numa situação dinâmica limitada em Vieira Filho (2004) e Vieira, Campos e Ferreira (2005). recursos escassos e intensificar a utilização de recursos abundantes. Como a oferta de terra é inelástica, os aumentos produtivos dependem do desenvolvimento tecnológico. As variedades de alto rendimento que respondem aos usos de fertilizantes anulam as restrições do crescimento econômico impostas pelo fator escasso, no caso a terra. De forma análoga, numa economia que apresente escassez relativa de trabalho, os melhoramentos de máquinas e implementos agrícolas são uma maneira de promover o aumento da produção. A mecanização agrícola propiciou um aumento da produtividade do trabalho e, consequentemente, uma expansão da área cultivada, já que foi capaz de poupar trabalho como recurso escasso.

O crescimento agrícola depende, em grande parte, da escolha da trajetória tecnológica mais ajustada ao processo produtivo dentre os possíveis caminhos. Para Hayami e Ruttan (1988, p. 99), “[...] Uma teoria de desenvolvimento agrícola deve incorporar o mecanismo pelo qual uma sociedade escolhe este caminho ótimo de mudança tecnológica para a agricultura". As mudanças técnicas são proporcionadas por efeitos de via dupla entre o segmento fornecedor de insumos tecnológicos, os centros de pesquisas e o setor produtor, como já tratado por Sahal (1985), Dosi (1984, 1988), Chiaromonte, Dosi e Orsenigo (1993) e Mowery e Rosenberg (2005).

[...] a mudança técnica é de natureza totalmente induzida. Há uma dimensão de oferta (exógena) para o processo, assim como uma dimensão de demanda (endógena). Além dos efeitos das dotações de recursos e do crescimento da demanda, a mudança técnica reflete o progresso da ciência e da tecnologia em geral. [...] Mesmo nestes casos, a taxa de adoção e o impacto sobre a produtividade das mudanças autônomas ou exógenas na tecnologia serão influenciados fortemente pelas condições de oferta de recursos e da demanda por produtos, já que estas forças se refletem através 
dos mercados de fatores e de produtos (HAYAMI e RUTTAN, 1988, p. 104).

Portanto, a inovação tecnológica significa aumentar a produtividade, seja da terra ou do trabalho, em termos de mudanças nos preços relativos dos insumos, sendo tais mudanças induzidas por novos conhecimentos no setor privado e público. A dinâmica do modelo é constituída pelo processo de adoção tecnológica dos agricultores, do fornecimento de insumos modernos e da geração de conhecimento por parte dos órgãos públicos e privados de pesquisa. Mesmo que a definição seja restritiva, o modelo trabalha com dois tipos de tecnologia: uma mecânica, que reduz o uso de trabalho, e outra biológica, poupadora de terra.

O funcionamento da mudança técnica induzida pode ser discutido a partir da Figura 4. Tem-se a configuração tanto da inovação mecânica na parte (a) quanto da biológica na (b). A curva de possibilidade de inovação $(C P I)$ é definida como uma envoltória das isoquantas unitárias, correspondentes às tecnologias alternativas desenvolvidas por uma dada pesquisa $^{20}$. As isoquantas (I) são curvas que apresentam uma mesma produção para distintas combinações de insumos produtivos. Nota-se que as transformações são dadas em dois períodos do tempo $(0$ para o inicial e 1 para o final), e que o equilíbrio produtivo (escolha da combinação dos insumos) é mostrado pela reta que tangencia o ponto de encontro entre a CPI e a $I$.

No que se refere à inovação mecânica, o eixo vertical é representado acima pelo trabalho e abaixo pela potência das máquinas e tratores

20 Segundo Nelson e Winter (1977, p. 57), "In many cases natural trajectories are specific to a particular technology or broadly defined 'technological regime'. We use the 'technological regime' language to refer to much the same kind of thing as Hayami and Ruttan mean by a meta production function. Their concept refers to a frontier of achievable capabilities, defined in the relevant economic dimensions, limited by physical, biological, and other constraints, given a broadly defined way of doing things. Our concept is more cognitive, relating to technicians' beliefs about what is feasible or at least worth attempting". As estratégias de pesquisa e desenvolvimento estão conectadas a certos regimes tecnológicos, os quais definem as direções do progresso. agrícolas, enquanto que, no eixo horizontal, tem-se o fator terra. No período inicial, o ponto de equilíbrio de custo mínimo é dado por $P$, expresso por uma combinação ótima de terra e trabalho e correspondido por uma relação de preços $x x$. Num segundo momento, um aumento do custo relativo do trabalho (dado pela linha $z z$ ) induz o desenvolvimento de uma inovação mecânica mais potente, que combine menos trabalho e mais terra, deslocando a $C P I_{0}$ para a $C P I_{1}$ e alterando a taxa marginal de substituição técnica da $I_{0}$ para a $\mathrm{I}_{1}^{21}$. O novo ponto de equilíbrio é dado por $Q$, o que implica uma relação complementar entre terra e energia expressa pela linha $(A, M)$. Nesta representação simplificada, pressupõe-se que a terra mais a energia são substitutas do trabalho.

Quanto à inovação biológica, ao contrário da tecnologia mecânica, busca-se a substituição de terra por outros insumos. De qualquer forma, o raciocínio microeconômico é análogo ao anterior. No eixo vertical, tem-se a terra e, na parte inferior, a infraestrutura da terra (como sistemas de irrigação e drenagem). No eixo horizontal, encontram-se os fertilizantes. O ponto de equilíbrio inicial é dado em $R$. No período subsequente, com o aumento do custo relativo da terra (a passagem da linha $b b$ para a $c c$ ), tem-se a indução de novas tecnologias (por exemplo, uma nova variedade que responda melhor à adubação), dada pelo deslocamento da $C P I_{0}$ para a $C P I_{1}$, em conjunto com a queda lateral de $I_{0}$ para a $I_{1}$. No novo ponto de equilíbrio $(S)$, é sugerida uma relação complementar entre fertilizantes e infraestrutura da terra, representada pela linha $(F, B)$.

Embora o referencial analítico apresentado seja um debate mais próximo da teoria evolucionária, é necessário fazer algumas considerações. De fato, a mudança técnica pode ser influenciada pela alteração dos preços relativos. Entretanto, a substituição automática de um insumo técnico pelo fator escasso não se processa na ausência

21 Perceba que o deslocamento da isoquanta é dado de forma não convencional, o que explica a real contribuição de Hayami e Ruttan (1988). Este deslocamento é para baixo, a ponto de alcançar os novos desenvolvimentos tecnológicos, e lateral, proporcionado pelo conhecimento externo e induzido pela mudança dos preços relativos dos insumos. 
Figura 4. Mudança técnica induzida na agricultura.
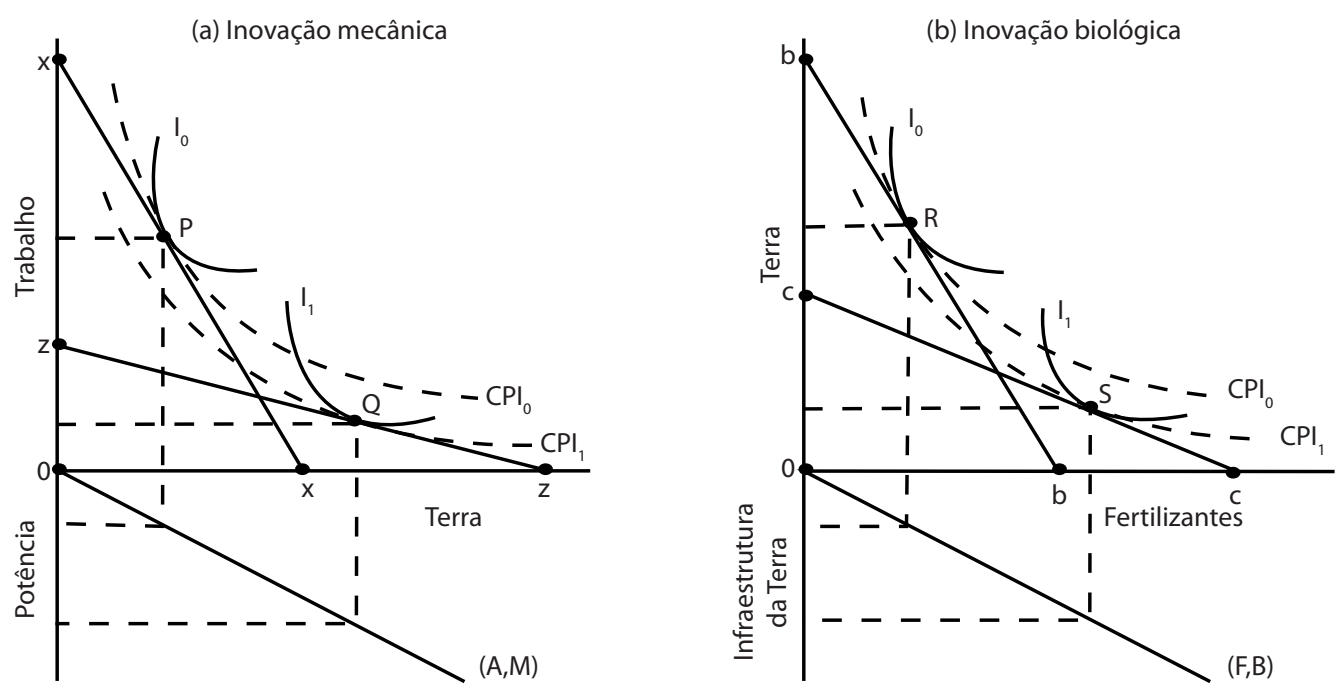

Fonte: Hayami e Ruttan (1988, p. 105).

de mudanças institucionais ${ }^{22}$. Nesse sentido, a teoria da inovação induzida fica condicionada à teoria institucionalista, pois o viés induzido da mudança técnica é mais complexo do que um ajuste de equilíbrio, como visto nesta seção. De acordo com o estudo crítico de Dall'Acqua (1983, p. 938), “[...] não é legítimo analisar o processo de desenvolvimento sob o prisma da alocação eficiente de recursos escassos [...]". Além disso, num ambiente multissetorial em que o capital é heterogêneo, não se deriva, a priori, a direção da relação capital/trabalho diante das mudanças nas taxas de salário e lucro.

De qualquer forma, para a compreensão da mudança tecnológica na agricultura, é importante enfatizar a forma pela qual os investimentos se conectam aos regimes tecnológicos, determinando, assim, os caminhos de dependência e o processo de aprendizado dos agricultores. Ao contrário de

22 A mudança tecnológica segundo a teoria da inovação induzida é resultado de um processo de sinalização dos preços relativos dos fatores. Não se refere ao simples processo de ajustamento à mudança de preços relativos ao longo de uma isoquanta, que ocorre em uma economia competitiva. Trata-se de uma decisão de gastos em unidades de pesquisa, poupadoras de capital e de trabalho em uma proporção que respeita a sinalização dada pela escassez relativa de fatores. $\mathrm{O}$ resultado é uma trajetória eficiente de redução de custos - ver Silveira (2002). um enfoque baseado apenas nos preços relativos, a mudança tecnológica na agricultura depende da trajetória tecnológica, como observada por Salles Filho (1993), e da acumulação do conhecimento, conforme Vieira Filho (2009) e Vieira Filho e Silveira (2011).

\section{Mudança tecnológica com aprendizado}

\subsection{Inovação, trajetória tecnológica e capacidade de absorção de conhecimento}

Esta seção busca explicar o caráter dinâmico do crescimento agrícola, baseando-se nas inovações, nas trajetórias tecnológicas e na ampliação da capacidade de absorção de conhecimento dos agricultores. Ao contrário da segunda seção, o desenvolvimento do segmento agrícola gera efeitos de encadeamento em toda a cadeia produtiva, não podendo ser considerado um setor de crescimento marginal. Procura-se conciliar a diversidade dos agentes e o caráter dinâmico das inovações, pressupondo instabilidade estrutural, racionalidade limitada e competição tecnológica ${ }^{23}$.

${ }^{23}$ Cf. Vercelli (1984), Simon (1979, 1987) e Nelson e Winter (1982). Essa abordagem alternativa é também 
Ruttan (1997) mostra que as fontes da mudança técnica são explicadas por elementos mais gerais da inovação induzida, da teoria evolucionária, dos caminhos de dependência e das trajetórias tecnológicas.

O estudo de Salles Filho (1993) é pioneiro no tratamento da dinâmica tecnológica da agricultura como um enfoque alternativo à compreensão de um setor tomador de preços (mercado concorrencial) e consumidor passivo de tecnologia (tomador de inovações). A dinâmica competitiva caracterizada por um processo de busca e seleção de inovações gera um conjunto de assimetrias, as quais se processam nos desdobramentos dos regimes e das trajetórias tecnológicas. Conforme este autor, a agricultura é usuária de tecnologia processada por fornecedores fora da unidade de produção, as inovações na agricultura são fundamentalmente de processos e os mecanismos de apropriabilidade das inovações pelos usuários são relativamente frágeis. Assim, o processo de inovação seria dado pela adoção e difusão de tecnologias, que seriam desenvolvidas por firmas cujas principais atividades estariam fora da produção agrícola. Todavia, os produtores de tecnologias estão organicamente vinculados à produção agrícola. $\mathrm{O}$ desenvolvimento tecnológico externo à unidade produtiva da agricultura não significa ausência de interações ${ }^{24}$.

O modelo de crescimento apresentado por Vieira Filho, Campos e Ferreira (2005) analisou a economia agrícola sob o enfoque da teoria evolucionária e, nesse sentido, percebeu que a competição tecnológica na agricultura era vista de forma schumpeteriana. Os resultados do modelo permitiram a identificação da região dinâmica agroindustrial, bem como os padrões

aplicada ao caso da agricultura familiar, como analisado em Buainain, Souza Filho e Silveira (2002).

${ }^{24}$ Os campos experimentais e o monitoramento das tendências de mercado são exemplos de interatividade entre a produção agrícola e o segmento fornecedor de insumos tecnológicos. Ademais, para compreender a ideia dos custos de transação na cadeia produtiva, ver Farina, Azevedo e Saes (1997). Para um contexto das políticas e instituições no agronegócio brasileiro, pesquisar a coletânea organizada por Ramos (2007). de comportamento da mudança tecnológica na agricultura.

Para construção do modelo de crescimento, definiu-se o capital como sendo uma composição de proporções fixas de fatores produtivos em uma situação dinâmica limitada. O modelo foi um instrumental do tipo geminado, o qual conciliou dois tipos de capital (estoque e fluxo) em uma mesma função de produção. $\mathrm{O}$ capital estoque era representativo das benfeitorias, das máquinas e dos equipamentos, enquanto o capital fluxo representava os defensivos, os fertilizantes e as sementes. O crescimento agrícola dependeria do crescimento do capital. Para conciliar a subdivisão acima, o crescimento, por exemplo, do capital estoque estava limitado ao crescimento do capital fluxo, e vice-versa.

A função de produção com proporções fixas foi uma forma de incorporar o caráter dinâmico das transformações econômicas ao longo do tempo (ver Figura 5). O caminho de expansão da produção estaria limitado pela combinação dos fatores produtivos entre dois raios, $\mathrm{OR}_{1}$ e $\mathrm{OR}_{2}$. Nos pontos A, B e C, a relação de insumos utilizados na produção variaria ao longo do tempo. Todavia, a substituição de fatores produtivos se restringiria a um limite superior e a um inferior, podendo compatibilizar as isoquantas de bico com o caráter evolucionário das transformações tecnológicas no correr do período.

É interessante perceber que esta representação esquemática da função de produção foi uma importante contribuição para a compreensão do comportamento agrícola, quando comparada ao modelo de inovação induzida de Hayami e Ruttan (1988). A inovação induzida era explicada pela diferença dos preços relativos dos insumos, procurando um viés que economizasse o fator escasso. Não obstante, a mudança técnica era definida por meio de um equilíbrio estável e por um deslocamento da curva de possibilidade de inovação e da isoquanta, sendo, em última instância, um deslocamento lateral para baixo da função de produção.

Em Vieira Filho, Campos e Ferreira (2005), a curva de produção representaria uma 
Figura 5. Mapa de isoquantas na agricultura para uma função de produção de proporções fixas em uma situação dinâmica limitada.

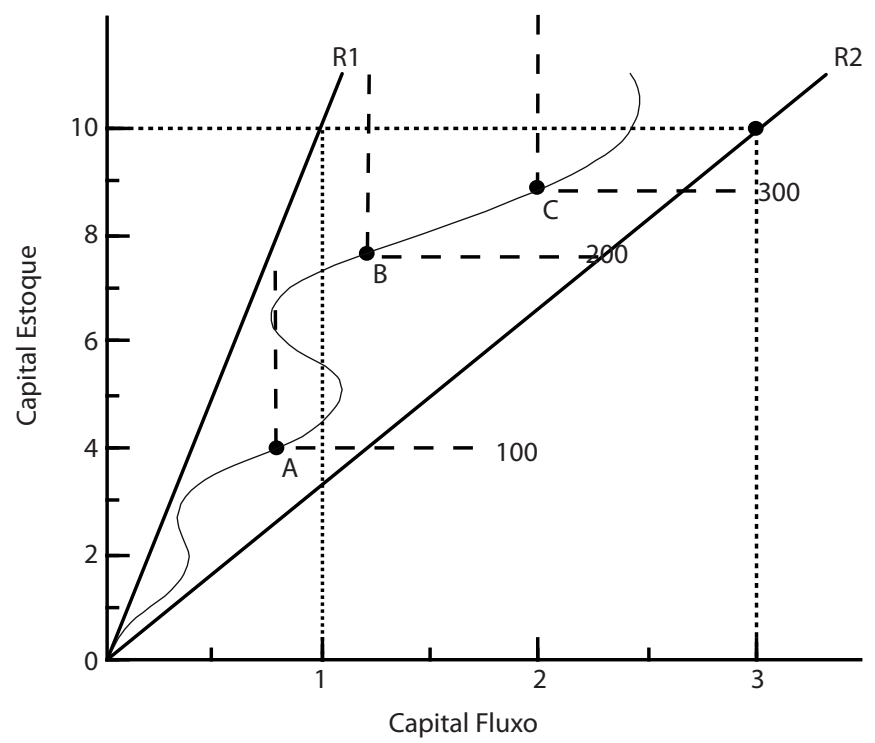

Fonte: Vieira Filho, Campos e Ferreira (2005, p. 472).

situação hipotética, já que o modelo construído era de simulação. Por um lado, o modelo de crescimento abordava a dinâmica do processo de pesquisa e desenvolvimento na busca por estratégias inovadoras, como no modelo de Nelson e Winter (1982). Por outro, apresentava uma lógica poupadora do fator menos produtivo, intensificando o uso do capital que proporcionasse maior retorno, dada a limitação de uma combinação mínima.

A quantidade produzida seria determinada como uma função de produção de proporções fixas entre duas formas de capital. A produção da atividade agrícola $i$ no período $t$ seria igual ao mínimo do quociente entre os capitais empregados $\left(K e_{i t}\right.$ ou $\left.K f_{i t}\right)$ e os seus respectivos coeficientes técnicos $\alpha$ e $\beta$. Logo: $K e_{i t}=\alpha . Q_{i t}$ e $K f_{i t}=\beta . Q_{i t}$. Assim, a produção $Q_{i t}$ se limitaria ao máximo dado pela combinação mínima entre esses dois fatores. Se $K e_{i t} / \alpha<K f_{i t} / \beta$, haveria sobra do segundo fator. Se o contrário ocorresse, $K e_{i \downarrow} / \alpha>K f_{i t} / \beta$, haveria excesso do capital estoque. Desse modo, a função de produção ficou determinada por:

$$
Q_{i t}=\min \left\{\frac{K e_{i t}}{\alpha} ; \frac{K f_{i t}}{\beta}\right\}
$$

A relação entre o capital fluxo e o capital estoque era dada por uma constante, sendo $K f_{i t} / K e_{i t}=z_{i t}$. Por outro lado, tinha-se que $\left(K f_{i t} / \beta\right) /\left(K e_{i t} / \alpha\right)=n$; tal que $\left(K f_{i t} / \beta\right) .\left(\alpha / K e_{i t}\right)=n$. Assim, fazendo-se a substituição, chegava-se ao resultado que n. $(\beta /$ $\alpha)=z_{i t}$. Os parâmetros $(\alpha$ e $\beta$ ) eram inicialmente determinados, sendo $n$ uma constante que definia a proporcionalidade entre os capitais. Então, no estado inicial do sistema, $z_{i t}$ era dado. Nesse sentido, $\alpha=1 / A e_{i t}$ e $\beta=1 / A f_{i t}$, em que $A e_{i t}$ era a produtividade do capital estoque e $A f_{i t}$ a produtividade do capital fluxo ${ }^{25}$.

Os resultados das simulações mostraram um contínuo crescimento da oferta produtiva e, ao mesmo tempo, um declínio dos níveis de preço. Os agentes foram subdivididos em inovadores e imitadores, tendo os primeiros maiores gastos em pesquisa e desenvolvimento. Ao se fazer uma interpretação conjunta da participação de mercado versus a lucratividade, mostrou-se que o esforço tecnológico era compensador no

\footnotetext{
25 O restante do modelo de crescimento seguiria a mesma lógica da modelagem de Nelson e Winter (1982). Porém, os parâmetros de cada capital seriam distintos. Ademais, ao rodar as simulações, a sequência das equações dependeria da escolha do fator produtivo.
} 
tocante à posição de mercado; entretanto, em termos de lucratividade, nem sempre o produtor inovador era o mais lucrativo. Apenas no longo prazo, as inovações beneficiariam, de um lado, os produtores inovadores e, de outro, excluiriam os menos competitivos. Em um ambiente de competição tecnológica, a competição pelos recursos produtivos nos complexos agroindustriais produtores de grãos levaria à busca permanente de inovações, caracterizando uma dinâmica evolucionária entre as atividades e uma maior concentração do capital setorial e regional.

Enquanto que Vieira Filho, Campos e Ferreira (2005) discutiram a importância do papel da mudança tecnológica no crescimento, Vieira Filho e Silveira (2011) concentraram a análise no mecanismo interno de aprendizado. Como identificado por Chiaromonte, Dosi e Orsenigo (1993), a adoção tecnológica influencia as condições da difusão dos novos conhecimentos. Para simular o comportamento agrícola, seria preciso tratar tanto da competição tecnológica quanto dos investimentos nas habilidades gerenciais e no aumento de capacidade de absorção, baseando-se na lógica de Coehn e Levinthal (1989).

A adoção de novas sementes (ou mesmo um crescimento do conteúdo tecnológico) no processo de produção pode exemplificar a importância do mecanismo de aprendizado. A semente seria o fator produtivo capaz de alterar o preço relativo dos demais insumos. A relação econômica produtiva das sementes e dos demais fatores produtivos seria ponto central para a compreensão do caso agrícola. Quanto maior fosse o gasto em investimento (inovação ou imitação), maior seria a capacidade de absorção de conhecimento externo e, consequentemente, mais eficiente o aprendizado, o que se relacionaria com menores custos produtivos e maiores produtividades.

A habilidade do agricultor em explorar o conhecimento externo é um componente crítico no reconhecimento do valor de uma nova informação, a qual pode ser assimilada e aplicada de diferentes formas na produção. Sementes mais modernas têm custo e grau tecnológico mais elevado quando comparadas às sementes tradicionais. As novas sementes podem gerar um efeito de economia no uso de outros fatores produtivos, como, por exemplo, redução de combustíveis e menor uso de herbicidas. Desta maneira, a produtividade associada à semente moderna será mais elevada e, se a nova informação for bem utilizada, ter-se-á um menor dispêndio de recursos financeiros nos outros fatores produtivos ${ }^{26}$.

A dinâmica agrícola e a diferenciação dos agentes são obtidas por meio de uma competição por maior eficiência econômica. A inovação tecnológica vinda do uso de uma nova semente pode gerar redução de custos e aumento de produtividade. A adoção de uma nova semente aumenta as chances de se obter um sucesso inovativo (redução de custos e aumento de produtividade). Entretanto, o comportamento da produtividade versus os custos dependerá da capacidade de absorção do conhecimento externo e do aprendizado de cada produtor. Diferentes agricultores têm distintas habilidades de aprendizado e de gerenciamento da tecnologia de forma mais eficiente.

\footnotetext{
${ }^{26}$ Em estudo realizado por Bragagnolo et al. (2007), numa análise de custos comparativos da produção da soja transgênica (RR) e da convencional no estado do Paraná, encontraram-se custos menores de produção para a soja transgênica se comparados aos da soja convencional. A estimativa de redução do custo total do plantio transgênico foi de 3,7\%. Embora o custo da semente transgênica (taxa tecnológica) tenha sido mais elevado (ao redor de $29 \%$ ), ocorreu uma diminuição das despesas decorridas da utilização de máquinas e equipamentos em 7,9\% e do consumo de combustível em $8,1 \%$. Além disso, tem-se redução das aplicações de herbicidas no plantio de transgênicos, sendo seu gasto reduzido em torno de 48\% quando comparado à soja convencional. Vale lembrar que estes resultados se diferenciam no âmbito regional, no aspecto microeconômico e na unidade produtiva. Pelo trabalho de Trigo et al. (2002), foram mostradas as principais mudanças da produção agrícola argentina, após a introdução do plantio de sementes transgênicas a partir de 1996. Explicou-se que a adoção de tecnologia externa, particularmente pela sua boa adequação às especificidades regionais da Argentina, favoreceu o crescimento agrícola, sem danos ambientais de qualquer natureza. De acordo com Evenson (2003), a revolução genética tem ajudado a aumentar a produtividade agrícola em geral e o uso de organismos geneticamente modificados é uma forma de países em desenvolvimento se beneficiarem de uma segunda revolução verde.
} 
Assim sendo, o grau de redução de custos e de aumento de produtividade, diante das habilidades gerenciais dos agricultores, foi o principal fato estilizado apresentado por Vieira Filho e Silveira (2011). É difícil a previsão de qualquer comportamento da produtividade e dos custos de produção, visto que os agricultores têm distintas capacidades de aprendizado e diversas formas de processamento da informação. A adoção de novas sementes não seria garantia de resultado bem-sucedido em termos de análise custo/benefício.

No modelo de aprendizado, o aumento do estoque de conhecimento $\left(Z_{i}\right)$ seria função do investimento do agricultor $\left(I_{i}\right)$, da sua respectiva capacidade de absorção $\left(\gamma_{i}\right)$, do efeito de transbordamento do mercado ou spillover $(\theta)$, do total de investimento realizado pelos outros produtores agrícolas $\left(\sum_{j \neq i} I_{j}\right)$ e do conhecimento externo $(E)$.

$$
Z_{i}=I_{i}+\gamma_{i}\left(\theta \sum_{j \neq i} I_{j}+E\right)
$$

A capacidade de absorção e o efeito de transbordamento assumem valores compreendidos entre zero e um. Quanto maior for a capacidade de absorção, maior será a habilidade do agricultor em apropriar-se do conhecimento oriundo dos investimentos dos demais produtores e mais eficiente será o uso do conhecimento externo. Quanto maior for o efeito de transbordamento, maior será a interação entre os agentes e mais fácil se tornará a difusão do conhecimento em rede.

O custo do produtor $\left(C_{i t}\right)$ é a soma do custo operacional $\left(\mathrm{CO}_{i}\right)$ mais o volume do investimento no período. O custo operacional é constante e determinado pelos custos administrativos, pelos gastos com mão de obra, pelos insumos e pelas despesas financeiras. É importante lembrar que a capacidade de absorção de cada agente tem a capacidade de reduzir parte do custo operacional. O parâmetro $\left(\psi_{i}\right)$ varia entre zero e um e determina o percentual a ser reduzido nos custos operacionais. Quanto maior a capacidade de absorção, maior será o desconto no custo operacional e, consequentemente, nos custos finais.

$$
C_{i t}=C O_{i} \cdot\left[1-\left(\psi_{i} \cdot \gamma_{i t}\right)\right]+I_{i t}
$$

Assim, a capacidade de absorção de cada agente pode influenciar não somente na assimilação de conhecimento externo como também na redução dos custos finais de produção a cada momento. O modelo de aprendizado procurou explicar o comportamento entre a produtividade, os custos e a capacidade de absorção de cada agricultor. No que tange ao processo de aprendizado, a capacidade de absorção aumenta em ordem crescente entre os agentes imitadores para os inovadores. O investimento em aprendizado busca aumentar a capacidade de absorção e, consequentemente, a captação de conhecimento externo. Portanto, o investimento na agricultura tem duas funções: i) gerar inovações tecnológicas, o que aumenta, de um lado, a produtividade; e ii) ampliar a capacidade de absorção de conhecimentos, o que reduz, de outro, os custos produtivos.

\section{Considerações finais}

O presente trabalho procurou, de um lado, discutir a incapacidade da literatura tradicional de interpretar o moderno setor agrícola, já que condiciona o seu desenvolvimento ao crescimento exógeno industrial. De outro, buscou-se mostrar, em linhas gerais, de que forma as inovações tecnológicas, a capacidade de absorção de conhecimentos e o processo de aprendizado dos produtores agrícolas influenciam na dinâmica produtiva.

Ao explorar a literatura da difusão do milho híbrido, do dualismo produtivo e da inovação induzida, percebeu-se que esta concepção de agricultura seria insuficiente para explicar os complexos arranjos produtivos de ciência e tecnologia voltados ao crescimento agrícola. Aumentar a produtividade da agricultura não é simplesmente ajustar os parâmetros da difusão, já que estes são influenciados pela dinâmica produtiva. O processo de modernização agrícola não pode ser visto inserido numa lógica de setor retardatário, em que o progresso técnico 
deteriora a renda do agricultor e depende do setor industrial. No que se refere à inovação induzida, a substituição técnica entre os insumos produtivos é mais complexa do que uma simples alternância dos preços relativos e uma acomodação de equilíbrio.

Algumas lições podem ser retiradas:

i) a agricultura deve ser compreendida por meio do papel do investimento no processo produtivo;

ii) os agricultores competem por uma melhor e mais eficiente combinação de insumos tecnológicos a ponto de adquirir vantagens comparativas dinâmicas;

iii) o investimento, por sua vez, gera novos produtos ou inovações tecnológicas, mas fundamentalmente, no caso agrícola, proporciona um aumento da capacidade de absorção de conhecimento externo.

A apresentação desse conteúdo se deu no intuito de compreender melhor a mudança tecnológica na agricultura e de situar as decisões e estratégias de investimento na produção, identificando as inovações, as trajetórias tecnológicas e o aprendizado como elementos centrais ao debate.

As habilidades gerenciais dos produtores são construídas para explorar e captar novas informações. Portanto, o processo de adoção tecnológica condiciona os parâmetros da difusão, e não o contrário. O setor agrícola pode ampliar as oportunidades tecnológicas dos provedores de insumos modernos. O efeito de ação e reação em cadeia proporciona crescimento em nichos tecnológicos, estabelecendo caminhos e trajetórias bem definidas. A indução tecnológica se associa aos elementos schumpeterianos de análise e às mudanças institucionais. A crítica ao desenvolvimento marginal diz respeito ao fato de a agricultura não corresponder à lógica de um setor retardatário no crescimento econômico. A mudança tecnológica dentro da agricultura é um fenômeno econômico mais amplo que compreende os processos de aprendizagem e de difusão do conhecimento.

\section{Referências bibliográficas}

BINSWANGER, H. P. A microeconomic approach to induced innovation. The Economic Journal, v. 84, n. 336, p. 940-958, dez. 1974a.

BINSWANGER, H. P. The measurement of technical change biases with many factors of production. The American Economic Review, v. 64, n. 6, p. 964-976, dez. 1974b.

BRAGAGNOLO, C. etal. Análise dos custos de produção da soja no Paraná: convencional $x$ transgênica (RR). In: CONGRESSO DA SOBER, 45., 2007, Londrina. Anais... Londrina: Sociedade Brasileira de Economia, Administração e Sociologia Rural, p. 19, 2007.

BUAINAIN, A. M., SOUZA FILHO, H. M. de e SILVEIRA, J. M. da. Inovação tecnológica na agricultura e a agricultura familiar. In: LIMA, D. M. de A. e WILKINSON, J. Inovação nas tradições da agricultura familiar. Brasília: Paralelo 15, Cap. 3, p. 47-81, 2002.

CHIAROMONTE, F., DOSI, G. e ORSENIGO, Luigi. Innovative learning and institutions in the process of development: on the microfoundation of growth regimes. In: THOMSON, R. (Org.). Learning and technological change. UK: Macmillan Press, p. 117-149, 1993.

COHEN, W. M. e LEVINTHAL, D. A. Absorptive capacity: a new perspective on learning and innovation. Administrative Science Quarterly, v. 35, p. 128-152, mar. 1990.

COHEN, W. M. e LEVINTHAL, D. A. Innovation and learning: the two faces of R\&D. The Economic Journal, v. 99 , p. 569-596, set. 1989.

COWAN, R. e JONARD, N. The dynamics of collective invention. Journal of Economic Behavior and Organizatio, v. 52, p. 513-532, 2003.

DALL'ACQUA, F. M. O problema da agregação de capital: uma crítica ao modelo de inovações induzidas de Hayami e Ruttan. Planejamento e Pesquisa Econômica, v. 13, n. 3, p. 921-944, dez. 1983.

DAVID, P. A contribution to the theory of diffusion. Stanford: Stanford Center for Research of Economic Growth, 1969. (Texto para Discussão, 71) apud SILVERBERG, G., DOSI, G. e ORSENIGO, L. Innovation, diversity and diffusion: a self-organisation model. The Economic Journal, v. 98, p. 1032-1054, dez. 1988.

DAVIES, S. The diffusion of process innovation. Cambridge: Cambridge University Press, 1979. apud SILVERBERG, G., DOSI, G. e ORSENIGO, L. Innovation, diversity and diffusion: a self-organisation model. The Economic Journal, v. 98, p. 1032-1054, dez. 1988. 
DOSI, G. Sources, procedures, and microeconomic effects of innovation. Journal of Economic Literature, v. 26 , p. $1120-1171$, set. 1988.

DOSI, G. Technical change and industrial transformation. New York: St. Martin's Press, 1984, p. 338.

EVENSON, R. E. GMO's: prospects for increased crop productivity in developing countries. New Haven: Yale University, 2003, p. 21. (Texto para Discussão, 878).

FAO - Food and Agriculture Organization. La situation mondiale de l'alimentation et de l'agriculture (The State of Food and Agriculture - SOFA). 2000.

FARINA, E. M. M. Q., AZEVEDO, P. F. de e SAES, M. S. M. Competitividade: mercado, estado e organizações. São Paulo: Singular, p. 286, 1997.

GASQUES, J. G. et al. Produtividade da agricultura brasileira e os efeitos de algumas politicas. Brasília: Mapa, 2012. (Mimeografado).

GASQUES, J. G. et al. Produtividade total dos fatores e transformações da agricultura brasileira: análise dos dados dos censos agropecuários. In: GASQUES, J. G., VIEIRA FILHO, J. E. R. e NAVARRO, Z. (Orgs.). A agricultura brasileira: desempenho, desafios e perspectivas. Brasília: Ipea, p. 19-44, 2010.

GEROSKI, P. A. Models of technology diffusion. Research Policy, v. 29, p. 603-625, 2000.

GRILICHES, Z. Hybrid corn revisited: a reply. Econometrica, v. 48, n. 6, p. 1463-1465, set. 1980.

GRILICHES, Z. Hybrid corn: an exploration in the economics of technological change. Econometrica, v. 25, n. 4, p. 501-522, out. 1957.

HAYAMI, Y. e RUTTAN, V. W. Desenvolvimento agrícola: teoria e experiências internacionais. Brasília: EMBRAPA, 1988. 583p. HIRSCHMAN, A. Transmissão interregional e internacional do crescimento econômico. In: SCHWARTZMAN, J. (Org.). Economia regional: textos escolhidos. Belo Horizonte: CEDEPLAR, 1977. p. 35-52.

IWAI, K. Schumpeterian dynamics: I - an evolutionary model of innovation and imitation. New Haven: Yale University, 1981a. 43p. (Texto para Discussão, 602).

IWAI, K. Schumpeterian dynamics: II - technological progress, firm growth and "economic selection". New Haven: Yale University, 1981b. 41p. (Texto para Discussão, 603).

MANSFIELD, E. Technical change and the rate of imitation. Econometrica, v. 29, n. 4, p. 741-766, out. 1961.

MELO, F. H. de. O problema alimentar no Brasil: a importância dos desequilíbrios tecnológicos. Rio de Janeiro: Paz e Terra, 1983.
METCALFE, J. S. Evolutionary economics and creative destruction. 3. ed. London: Routledge, 2002. 153p.

MOWERY, D. C. e ROSENBERG, N. Trajetórias da inovação: a mudança tecnológica nos Estados Unidos da América no século XX. Campinas: Unicamp, 2005. 230p.

NELSON, R. R. e WINTER, S. G. An evolutionary theory of economic change. Cambridge, Mass.: Harvard University Press, 1982.

NELSON, R. R. e WINTER, S. G. In search of useful theory of innovation. Research Policy, v. 6, p. 36-76, 1977.

NICHOLLS, W. H. Paiva e o dualismo tecnológico na agricultura: um comentário. Pesquisa e Planejamento, v. 3, n. 1, p. 15-50, mar. 1973.

PAIVA, R. M. Modernização e dualismo tecnológico na agricultura. Pesquisa e Planejamento, v. 1, n. 2, p. 171-234, dez. 1971.

PAIVA, R. M. Modernização e dualismo tecnológico na agricultura: respostas aos comentários dos professores Nicholls e Schuh. Pesquisa e Planejamento, v. 3, n. 1, p. 95-116, mar. 1973.

PAIVA, R. M. Modernização e dualismo tecnológico na agricultura: uma reformulação. Pesquisa e Planejamento, v. 5, n. 1, p. 117-161, jun. 1975.

PERROUX, F. O conceito de pólo de crescimento. In: SCHWARTZMAN, J. (Org.). Economia regional: textos escolhidos. Belo Horizonte: CEDEPLAR, 1977. p. 145156.

POSSAS, M. L., SALLES-FILHO, S. e SILVEIRA, J. M. da. An evolutionary approach to technological innovation in agriculture: some preliminary remarks. Research Policy, v. 25, p. 933-945, fev. 1996.

RAMOS, P. (Org.). Dimensões do agronegócio brasileiro: políticas, instituições e perspectivas. Brasília: MDA, 2007. 360p.

RUTTAN, V. W. Induced innovation, evolutionary theory and path dependence: sources of technical change. The Economic Journal, v. 107, n. 444, p. 15201529 , set. 1997.

SADOULET, E. e DE JANVRY, A. Transactions costs and agrarian institutions. In: __. Quantitative development policy analysis. Baltimore: The Johns Hopkins University Press, 1995. cap. 9, p. 241-272.

SAHAL, D. Technological guideposts and innovation avenues. Research Policy, v. 14, p. 61-82, 1985.

SALLES FILHO, S. L. M. A dinâmica tecnológica da agricultura: perspectivas da biotecnologia. 1993. 239p. 
Tese (Doutorado em Teoria Econômica) - Unicamp, Campinas, 1993.

SCHUH, G. Edward. Modernização e dualismo tecnológico na agricultura: alguns comentários. Pesquisa e Planejamento, v. 3, n. 1, p. 51-94, mar. 1973.

SCHULTZ, T. W. Knowledge, Agriculture and Welfare. Science Studies, v. 2, n. 4, p. 361-368, out. 1972.

SCHULTZ, T. W. Transforming traditional agriculture. New Haven, Connecticut: Yale University Press, 1964.

SILVA, C. R. L. da. Inovação tecnológica e distribuição de renda: impacto distributivo dos ganhos de produtividade da agricultura brasileira. São Paulo: IEA, 1995. 245p.

SILVEIRA, J. M. F. J. da. Inovação tecnológica e crescimento: das teorias de inovação induzida às teorias de crescimento endógeno. 2002. 225p. Tese (Doutorado) Instituto de Economia, Unicamp, Campinas, 2002.

SILVERBERG, G., DOSI, G. e ORSENIGO, L. Innovation, diversity and diffusion: a self-organisation model. The Economic Journal, v. 98, p. 1032-1054, dez. 1988.

SIMON, H. A. Bounded rationality. London: MIT Press, 1987.

SIMON, H. A. From substantive to procedural rationality. In: HAHN, F. e HOLLIS, M. (Orgs.). Philosophy and economic theory. London: Oxford University Press, 1979.

STONEMAN, P. e IRELAND, N. J. The role of supply factors in the diffusion of new process technology. Economic Journal. Conference Papers, v. 93, p. 65-77,
1983. apud SILVERBERG, G., DOSI, G. e ORSENIGO, L. Innovation, diversity and diffusion: a self-organisation model. The Economic Journal, v. 98, p. 1032-1054, dez. 1988.

TRIGO, E., CHUDNOVSKY, D., CAP, E. e LÓPEZ, A. Genetically modified crops in Argentine agriculture: an open ended story. Buenos Aires: Libros del Zorzal, 2002. 122p.

VEIGA, J. E. da. Uma linha estratégica de desenvolvimento agrícola. Revista de Economia Política, v. 12, n. 2, p. 88-105, abr.jun. 1992.

VERCELLI, A. Keynes, Schumpeter, Marx and the structural instability of capitalism. In: DELEPLACE, G. e MAURISSON, P. (Org.) L'heterodoxie dans la pensee economique: K. Marx, J. M. Keynes et J. A. Schumpeter. Paris: Anthropos, 1984.

VIEIRA FILHO, J. E. R., CAMPOS, A. C. e FERREIRA, C. M. de C. Abordagem alternativa do crescimento agrícola: um modelo de dinâmica evolucionária. Revista Brasileira de Inovação, v. 4, n. 2, p. 425-476, jul./ dez. 2005.

VIEIRA FILHO, J. E. R. e SILVEIRA, J. M. F. J. da. Modelo evolucionário de aprendizado agrícola. Revista Brasileira de Inovação, v. 10, n. 2, p. 265-300, jul./dez. 2011.

VIEIRA FILHO, J. E. R. Abordagem evolucionária da dinâmica do setor agrícola. 2004. 96p. Dissertação (Mestrado em Economia) - UFV, Viçosa, 2004.

VIEIRA FILHO, J. E. R. Inovação tecnológica e aprendizado agrícola: uma abordagem schumpeteriana. 2009. 154p. Tese (Doutorado em Teoria Econômica) - Unicamp, Campinas, 2009. 